УДК 582.998.2:547.587

\title{
СРАВНИТЕЛЬНЫЙ АНАЛИЗ АНТИОКСИДАНТНОЙ АКТИВНОСТИ СОКОВ КАЛАНХОЕ
}

\author{
() Н.Н. Сажина ${ }^{1 *}$, П.В. Лапиин ${ }^{2}$ Н.В. Загоскина ${ }^{2}$, Е.И. Короткова ${ }^{3}$, В.М. Мисин ${ }^{1}$ \\ ${ }^{1}$ Институт биохимической фризики им. Н.М. Эмануэля РАН, ул. Косыгина, 4, \\ Москва, 119334 (Россия), e-mail: Natnik48s@yandex.ru \\ ${ }^{2}$ Институт фозиологии растений им. К.А. Тимирязева РАH, \\ ул. Ботаническая, 35, Москва (Россия), e-mail: phenolic@ippras.ru \\ ${ }^{3}$ Томский политехнический университет, пр. Ленина, 30, Томск, 634050, \\ (Россия), e-mail: eikor@mail.ru
}

В настоящее время представляет интерес изучить биологическую, в том числе и антиоксидантную, активность различных лекарственных растений с целью поиска среди них наиболее активных источников биологически активных соединений. В данной работе с этой целью проведен сравнительный анализ результатов измерений антиоксидантной активности соков 14 различных видов каланхое тремя методами: амперометрическим, вольтамперометрическим и хемилюминесцентным. Среди изученных образцов выявлены два наиболее активных с точки зрения АОА представителя рода Каланхое: K. scapigera и K. rhombopilosa. Они могут оказаться более богатыми источниками биологически активных соединений по сравнению с использующимися в настоящее время видами каланхое.

Ключевые слова: антиоксиданты, амперометрический, вольтамперометрический, хемилюминесцентный методы, фенольные соединения, Каланхое.

\section{Введение}

Род Каланхое (Kalanchoe Adans.) насчитывает в настоящее время более 130 различных видов. Эти растения широко культивируются по всему миру. Представители рода Каланхое - суккулентные растения с сочными водозапасающими листьями причудливой формы [1]. В основном они используются как декоративные, но некоторые виды применяются и в лечебных целях, так как в их листьях содержатся полезные минеральные соли, органические кислоты и многочисленные полифенольные соединения [2, 3]. Образование и накопление этих соединений в процессе вторичного метаболизма зависит от многочисленных факторов окружающей среды и от генетических особенностей растения. Фенольные соединения и обуславливают, главным образом, биологическую, в том числе и антиоксидантную, активность (АОА) того или иного вида растения, т.е. способность его компонент ингибировать окислительные свободнорадикальные про-

Сажина Наталья Николаевна - старший научный сотрудник, кандидат физико-математических наук, тел.: (495) 939-74-18, e-mail: Natnik48s@ @andex.ru

Лапшин Петр Владимирович - научный сотрудник, кандидат биологических наук, тел.: (499) 977-94-33, e-mail: p.lapshin@mail.ru

Загоскина Нататья Викторовна - ведущий научный сотрудник, доктор биологических наук, тел.: (499) 977-94-33, e-mail: nzagoskina@mail.ru Короткова Елена Ивановна - доцент кафедры физической и аналитической химии, доктор химических наук, тел.: (3822) 56-38-32, e-mail: eikor@mail.ru Мисин Вячеслав Михайлович - заведующий лабораторией, доктор химических наук, тел.: (495) 939-74-09, e-mail: misin@sky.chph.ras.ru; цессы. Особенно хорошо изучены в настоящее время биохимический состав и целебные свойства соков и экстрактов Каланхое перистого и Каланхое Дегремона [2-4]. Однако результатов целенаправленных научных исследований антиоксидантных свойств этих и других видов Каланхое практически нет [5, 6].

В настоящей работе проведен сравнительный анализ результатов измерений АОА соков различных видов Каланхое тремя методами: амперометрическим, вольтамперометрическим и хемилюминесцентным с целью выявления среди них наиболее активных продуцентов биологически активных соединений.

\footnotetext{
* Автор, с которым следует вести переписку.
} 


\section{Экспериментальная часть}

Объектами исследования явились 34 представителя рода Каланхое (Kalanchoe L.), выращиваемые в коллекции суккулентов в Институте физиологии растений им. К.А.Тимирязева РАН в Москве в условиях оранжереи при естественном освещении. Соки были выжаты из листьев этих растений, хранились в холодильнике при температуре $-12{ }^{\circ} \mathrm{C}$, а для измерений размораживались до комнатной температуры и при необходимости разбавлялись дистиллированной водой. Измерения АОА проводились двумя непрямыми электрохимическими методами: амперометрическим и вольтамперометрическим, и прямым, использующим окислительную схему, хемилюминесцентным (ХЛ) методом.

Амперометрический метод, реализованный в приборе «Цвет-Яуза-01-АА», позволяет определить суммарную активность АО фенольной природы [7]. Сущность его заключается в измерении электрического тока, возникающего при окислении исследуемого вещества на поверхности рабочего электрода при величине электрического потенциала $0-1,3$ В. При таких значениях потенциала происходит окисление $-\mathrm{OH}$ групп природных фенольных $\mathrm{AO}(\mathrm{R}-\mathrm{OH})$. Электрохимическое окисление, протекающее по схеме $\mathrm{R}-\mathrm{OH} \rightarrow$ $\mathrm{R}-\mathrm{O}^{\bullet}+\mathrm{e}^{-}+\mathrm{H}^{+}$, может быть использовано, по предположению авторов [8], как модельное при измерении активности поглощения свободных радикалов. Захват свободных радикалов осуществляется в соответствии с реакцией $\mathrm{R}-\mathrm{OH} \rightarrow \mathrm{R}-\mathrm{O}^{\bullet}+\mathrm{H}^{*}$. В этом случае способность к захвату свободных радикалов фенольными соединениями может измеряться величиной их окисляемости на рабочем электроде амперометрической ячейки [8]. При прохождении пробы через ячейку регистрируется ток электрохимического окисления АО, который сравнивается с током, полученным в тех же условиях для эталонного образца с известной концентрацией (галловой кислотой ГК). Суммарная активность фенольных АО, степенью которой служит площадь под кривой тока окисления, определяется по калибровочной зависимости окисляемости ГК от ее концентрации, т.е. в единицах содержания ГК. Погрешность измерения величины АОА (или суммарного содержания АО в мг/л ГК) с учетом воспроизводимости результатов составила $10 \%$.

В вольтамперометрическом методе [9] в качестве модельной реакции используется процесс электровосстановления кислорода (ЭВ $\mathrm{O}_{2}$ ) на ртутно-пленочном электроде, идущий по механизму, аналогичному восстановлению кислорода в живых клетках. Реакция ЭВ $\mathrm{O}_{2}$ на ртутно-пленочном электроде идет в несколько стадий с генерацией на поверхности электрода активных форм кислорода:

$$
\begin{gathered}
\mathrm{O}_{2}+\mathrm{e}^{-} \rightleftarrows \mathrm{O}_{2}^{-} \\
\mathrm{O}_{2}^{-}+\mathrm{H}^{+} \rightleftarrows \mathrm{HO}_{2} \\
\mathrm{HO}_{2}{ }^{-}+\mathrm{H}^{+}+\mathrm{e}^{-} \rightleftarrows \mathrm{H}_{2} \mathrm{O}_{2} \\
\mathrm{H}_{2} \mathrm{O}_{2}+2 \mathrm{H}^{+}+2 \mathrm{e}^{-} \rightleftarrows 2 \mathrm{H}_{2} \mathrm{O}
\end{gathered}
$$

При определении АОА различных соединений авторами метода [9] предложено использовать пер-

\begin{tabular}{|c|c|c|c|}
\hline № групп & Названия веществ & Влияние на ЭВ $\mathrm{O}_{2}$ & Предполагаемый электродный механизм \\
\hline 1 & $\begin{array}{c}\text { Каталаза, фталоцианины } \\
\text { металлов, гумминовые } \\
\text { кислоты }\end{array}$ & $\begin{array}{c}\text { Увеличение тока ЭВ О}, \\
\text { сдвиг потенциала в от- } \\
\text { рицательную область }\end{array}$ & $\begin{array}{c}\text { Механизм ЕС* с последующей реакцией дис- } \\
\text { пропорционирования перекиси водорода и } \\
\text { частичной регенерацией молекулярного ки- } \\
\text { слорода }\end{array}$ \\
\hline 2 & $\begin{array}{c}\text { Соединения фенольной } \\
\text { природы, витамины А, Е, } \\
\mathrm{C}, \mathrm{B}, \text { убихинон, глюкоза }\end{array}$ & $\begin{array}{c}\text { Уменьшение тока ЭВ О}, \\
\text { сдвиг потенциала в по- } \\
\text { ложительную область }\end{array}$ & $\begin{array}{c}\text { Механизм ЕС с последующей химической } \\
\text { реакцией взаимодействия АО с активными } \\
\text { кислородными радикалами }\end{array}$ \\
\hline 3 & $\begin{array}{c}\mathrm{N}, \mathrm{S}, \mathrm{Se}-\text { содержащие со- } \\
\text { единения, амины, амино- } \\
\text { кислоты, активные альде- } \\
\text { гиды }\end{array}$ & $\begin{array}{c}\text { Уменьшение тока ЭВ } \mathrm{O}_{2}, \\
\text { сдвиг потенциала в от- } \\
\text { рицательную область }\end{array}$ & $\begin{array}{c}\text { Механизм СЕС с предшествующей и после- } \\
\text { дующей химическими реакциями взаимодей- } \\
\text { ствия АО с кислородом и его активными ра- } \\
\text { дикалами }\end{array}$ \\
\hline 4 & $\begin{array}{c}\text { Супероксидисмутаза } \\
\text { (СОД), порфирины метал- } \\
\text { лов, цитохром C }\end{array}$ & $\begin{array}{c}\text { Увеличение тока ЭВ } \mathrm{O}_{2}, \\
\text { сдвиг потенциала в по- } \\
\text { ложит. область }\end{array}$ & $\begin{array}{c}\text { Механизм ЕС с каталитическим восстановле- } \\
\text { нием кислорода через образование промежу- } \\
\text { точного комплекса }\end{array}$ \\
\hline
\end{tabular}
вую волну ЭВ $\mathrm{O}_{2}$, соответствующую стадиям (1) - (3). Различные вещества по разному влияют на процесс ЭВ $\mathrm{O}_{2}$ (табл. 1).

Таблица 1. Влияние различных веществ на процесс электровосстановления кислорода

*Примечание: Е - электродная стадия процесса, С - химическая реакция. 
За критерий АОА исследуемых образцов была принята величина А, отражающая изменение концентрации кислорода и его активных радикалов $\left(\mathrm{O}_{2}{ }^{-}, \mathrm{HO}_{2}\right)$, прореагировавших с АО в процессе ЭВ $\mathrm{O}_{2}$ : $\mathrm{A}=$ $\mathrm{C}_{0} \cdot\left(1-\mathrm{I} / \mathrm{I}_{0}\right)$, где $\mathrm{I}, \mathrm{I}_{0}$ - максимальные токи ЭВ $\mathrm{O}_{2}$ соответственно в присутствии и в отсутствие АО в растворе фонового электролита, $\mathrm{C}_{0}$ - исходная концентрация кислорода (мкмоль/л) [9]. Для каждого образца было проведено 3-4 замера, и результаты усреднялись. Среднеквадратичное отклонение А от среднего значения для исследованных образцов составило не более $30 \%$.

В хемилюминесцентном (ХЛ) методе измерения АОА использовалась схема окисления системы «гемоглобин - пероксид водорода - люминол» [10]. Отличительной особенностью этой системы от других окислительных систем является то, что образующиеся в ней радикалы могут инициировать свободнорадикальные реакции in vivo. Взаимодействие $\mathrm{H}_{2} \mathrm{O}_{2}$ с метНb сопровождается разрушением гема и выходом из него ионов железа, которое участвует в образовании $\mathrm{OH}^{\bullet}$. Кроме того, в результате этого взаимодействия образуются еще феррил-радикалы $\left.\left(\mathrm{Hb}^{\bullet+}\right)-\mathrm{Fe}^{4+}=\mathrm{O}\right)$. Образующиеся радикалы инициируют окисление люминола, в процессе которого образуется эндопероксид люминола $\mathrm{LO}_{2}{ }^{2-}$, а далее 3-аминофталат дианион в возбужденном состоянии $\left(\mathrm{AP}^{2-}\right)^{*}$, при переходе которого в основное состояние высвечивается квант света с длиной волны 425 нм. Введение в систему Нb- $\mathrm{H}_{2} \mathrm{O}_{2}$-люминол АО приводит к изменению кинетики ее ХЛ и увеличению латентного периода $t$, который увеличивается прямо пропорционально концентрации добавляемого AO [10]. Для реализации данного метода в настоящей работе был использован прибор «Lum5773». За критерий АОА исследуемых образцов принималось значение тангенса угла наклона прямой (k, мкг $\left.{ }^{-1}\right)$, описывающей зависимость относительного латентного периода $\left(\mathrm{t} / \mathrm{t}_{0}\right) \mathrm{XЛ}$ свечения от массы образца $\left(\mathrm{m}\right.$, мкг), вводимой в ХЛ ячейку: $\mathrm{t} / \mathrm{t}_{0}=\mathrm{km}+1, \mathrm{t}_{0}$ - латентный период в отсутствие образца. Погрешность измерения АОА данным методом с учетом повторяемости результатов составила 15\%. На рисунке 1 приведена характерная динамика развития ХЛ свечения для различных значений $\mathrm{m}$, а на рисунке 2 - зависимости t/t $\mathrm{t}_{0}$ от m для некоторых образцов соков, по которым определялись значения АОА (k).

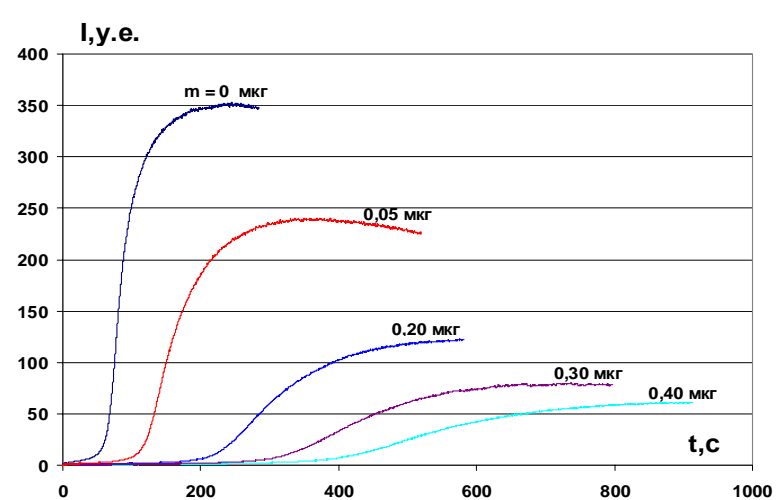

Рис. 1. Характерная динамика развития хемилюминесцентного (ХЛ) свечения для различных значений массы образца $\mathrm{m}$, вводимой в рабочую ячейку

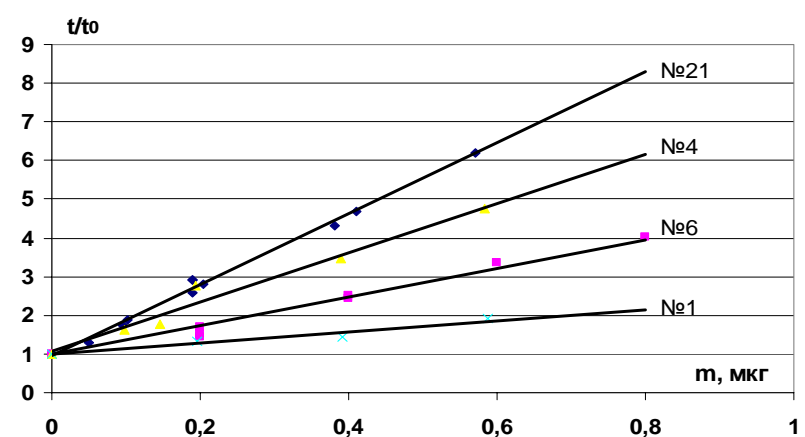

Рис. 2. Зависимость относительного латентного периода $\left(\mathrm{t} / \mathrm{t}_{0}\right)$ ХЛ свечения от массы образца $\mathrm{m}$, вводимого в ячейку, для соков разных видов Каланхое

\section{Обсуждение результатов}

В таблице 2 представлены результаты измерений суммарной АОА фенольных антиоксидантов амперометрическим методом для 34 образцов соков Каланхое. Наибольшей активностью обладают соки таких видов Каланхое, как K. scapigera №11 и K. rhombopilosa №21 (1981 и 1911 мг/л ГК, соответственно), наименьшей - соки K. blossfeldiana и K. laetivirens (205 и 186 мг/л ГК). Наиболее распространенные и изученные виды Каланхое, такие как K. pinnata и K. daigremontiana, показали достаточно низкие относительно других видов Каланхое уровни накопления и активности фенольных АО (294 и 550 мг/л ГК, соответственно).

Для сопоставления результатов измерений АОА образцов соков Каланхое, представленных в таблице, с результатами других методов были выбраны 14 образцов, имеющих разный спектр значений С (в таблице они выделены). 
Таблица 2. Суммарная АОА образцов соков Каланхое, измеренная амперометрическим методом

\begin{tabular}{c|l|c|c|l|c}
\hline $\begin{array}{c}\text { № } \\
\text { образца }\end{array}$ & \multicolumn{1}{|c|}{$\begin{array}{c}\text { Видовое название } \\
\text { Каланхое }\end{array}$} & $\begin{array}{c}\text { Ампером. } \\
\text { С, мг/л ГК }\end{array}$ & $\begin{array}{c}\text { № } \\
\text { образца }\end{array}$ & $\begin{array}{c}\text { Видовое название } \\
\text { Каланхое }\end{array}$ & $\begin{array}{c}\text { Ампером. } \\
\text { СГ/л ГК }\end{array}$ \\
\hline $\mathbf{1}$ & K.pinnata & $\mathbf{2 9 4}$ & $\mathbf{1 8}$ & K.millotii & $\mathbf{1 0 7 0}$ \\
$\mathbf{2}$ & K.beauverdii & $\mathbf{7 3 0}$ & $\mathbf{1 9}$ & K.fedtschenkoi & $\mathbf{6 0 4}$ \\
3 & K.orgyalis & 393 & 20 & K.serrata & 383 \\
$\mathbf{4}$ & K.imperialis & $\mathbf{8 7 8}$ & $\mathbf{2 1}$ & K.rhombopilosa & $\mathbf{1 9 1 1}$ \\
5 & K.tomentosa & 593 & 22 & K.kalandiva & 505 \\
$\mathbf{6}$ & K.daigremontiana & $\mathbf{5 5 0}$ & $\mathbf{2 3}$ & K.laciniata & $\mathbf{3 5 8}$ \\
7 & K.thyrsiflora & 220 & 24 & K.tubiflora & 423 \\
$\mathbf{8}$ & K.hildebrandtii & $\mathbf{1 2 6 5}$ & 25 & K.longiflora & 330 \\
9 & K.velutina & 545 & 26 & K.bracteata & 265 \\
10 & K.beharensis v.aureoaeneu & 368 & $\mathbf{2 7}$ & K.crenata & $\mathbf{3 8 0}$ \\
$\mathbf{1 1}$ & K.scapigera & $\mathbf{1 9 8 1}$ & $\mathbf{2 8}$ & K.nyikae & $\mathbf{5 1 4}$ \\
12 & K.citrina & 328 & 29 & K.sedoides & 342 \\
13 & K.Xkewensis & 301 & $\mathbf{3 0}$ & K.blossfeldiana & $\mathbf{2 0 5}$ \\
14 & K.serratifolia & 355 & 31 & K.blossfeldiana mini & 278 \\
15 & K.germanae & 321 & 32 & K.laetivirens & 186 \\
16 & K.syncepala & 247 & $\mathbf{3 3}$ & K.figuereidoi & $\mathbf{5 0 5}$ \\
17 & K.gastonis-bonnieri & 403 & 34 & K.pubescens & 388 \\
\hline
\end{tabular}

Для вольтамперометрического метода на рисунке 3 приведены типичные вольтамперограммы токов ЭВ $\mathrm{O}_{2}$, полученные для соков Каланхое. Вольтамперограммы, определяемые соединениями второй группы таблицы 1 (рис. 3а), показали 8 образцов соков (№4, 8, 18, 21, 23, 28, 30, 33), в остальных доминирующий характер взаимодействия компонентов с кислородом и его радикалами имеет не фенольную, а каталитическую природу и протекает по механизму, характерному для веществ 4 группы таблицы 1 (рис. 3б). Однако для всех образцов величина смещения потенциалов максимумов токов ЭВ О 2 увеличивается в соответствии с ростом суммарной AOА фенольных соединений, измеренной амперометрией. Для этой группы веществ (R$\mathrm{OH})$ предложен следующий «условный» механизм взаимодействия с активными формами кислорода [9]:

$$
\begin{gathered}
\mathrm{O}_{2}+\mathrm{e}^{-} \rightleftarrows \mathrm{O}_{2}^{-}+\mathrm{R}-\mathrm{OH} \rightleftarrows \mathrm{HO}_{2}{ }^{-}+\mathrm{R}-\mathrm{O}^{\circ} \\
\mathrm{HO}_{2}{ }^{-}+\mathrm{R}-\mathrm{OH} \rightleftarrows \mathrm{H}_{2} \mathrm{O}_{2}+\mathrm{R}-\mathrm{O}^{\circ}
\end{gathered}
$$

Согласно теории электродных процессов, показателем термодинамики электрохимических процессов является потенциал полуволны тока ЭВ $\mathrm{O}_{2}$, который описывается классическим уравнением Нернста, имеющим в случае электродного процесса (5) при температуре $\mathrm{T}=+25^{\circ} \mathrm{C}$ следующий вид:

$$
\mathrm{EO} 2 / \mathrm{O} 2 \cdot-=\mathrm{Eo} O 2 / \mathrm{O} 2 \cdot-+0,059 \cdot \lg (\mathrm{CO} 2 / \mathrm{CO} 2 \cdot-)
$$

Если супероксид кислорода $\left(\mathrm{O}_{2}{ }^{--}\right)$в реакции (5) реагирует с антиоксидантом $(\mathrm{R}-\mathrm{OH})$, то $\mathrm{C}_{\mathrm{O} 2-}$ - уменьшается, а потенциал увеличивается согласно (7), и максимум тока ЭВ $\mathrm{O}_{2}$ сдвигается в положительную область. Значения сдвига потенциала составили для исследованных образцов от 20 до 120 мВ. Увеличение же максимума тока ЭВ $\mathrm{O}_{2}$ относительно фонового для некоторых образцов соков связано, по-видимому, с образованием в процессе ЭВ $\mathrm{O}_{2}$ разного рода промежуточных металлокомплексов, которые действуют как катализаторы проходящих химических реакций подобно супероксиддисмутазе (СОД) [11].

На диаграммах рисунка 4 представлены результаты измерений АОА 14 образцов соков из таблицы 2 описанными выше методами. Для амперометрии диаграмма значений АОА построена в порядке убывания (С, мг/л ГК) (рис. 4а). Результаты измерений активности этих образцов по отношению к кислороду и его радикалам в процессе ЭВ $\mathrm{O}_{2}$ (А, мкмоль/л) приведены на рисунке 4б. Монотонность убывания А нарушают образцы №18, №2, №6, демонстрируя достаточно высокие значения АОА. По-видимому, активность компонентов в этих образцах и промежуточных соединений, образующихся в процессе ЭВ $\mathrm{O}_{2}$, определяется не только фенольными соединениями. Коэффициент корреляции результатов, полученных этими методами, составил $\mathrm{r}=0,83$. На рисунке 4в приведены результаты измерений степени ингибирования окисления системы « $\mathrm{Hb}-\mathrm{H}_{2} \mathrm{O}_{2}$ - люминол» указанными соками Каланхое ХЛ методом (k, мкг $\left.{ }^{-1}\right)$. Видно, что монотонность уменьшения активности на этой диаграмме несколько лучше, чем на рисунке 4б, а корреляция с амперометрическим методом выше и составила $\mathrm{r}=0,89$. Меньшее значение имеет коэффициент корреляции между результатами вольтамперометрического и ХЛ-методов ( $\mathrm{r}=0,81)$. 
a)

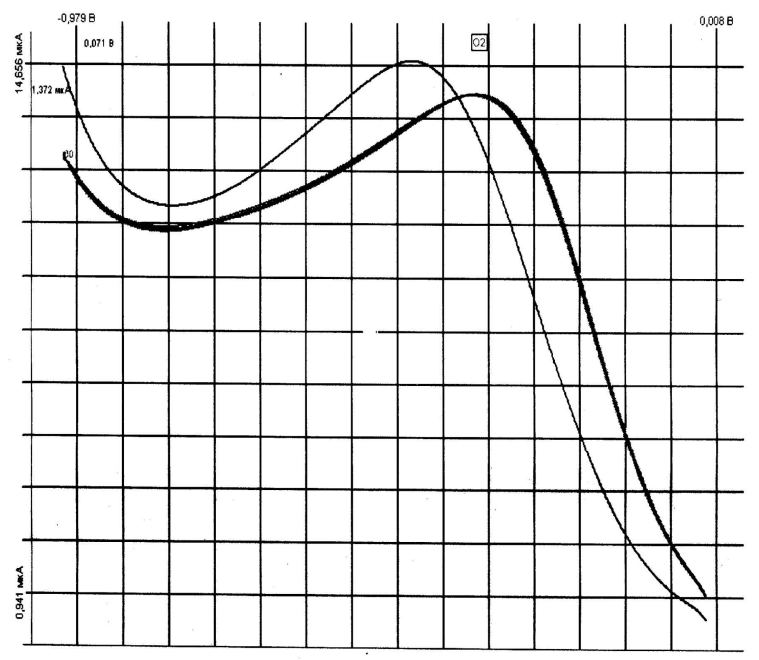

б)

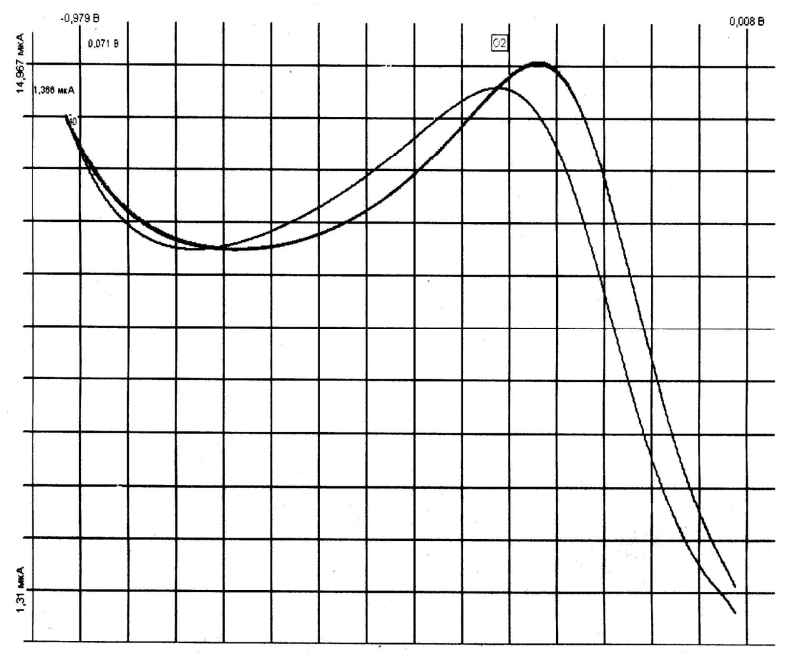

Рис. 3. Вольтамперограммы тока электровосстановления кислорода в отсутствие (левые тонкие кривые) и присутствии (правые кривые) сока Каланхое ( $\mathrm{V}=20$ мкл) для образцов, содержащих соединения второй группы (а) и четвертой группы (б) таблицы 1. Развертка потенциала справа налево от 0 до -1,0 B; по вертикальной оси - ток I (цена деления 1,37 мкА)
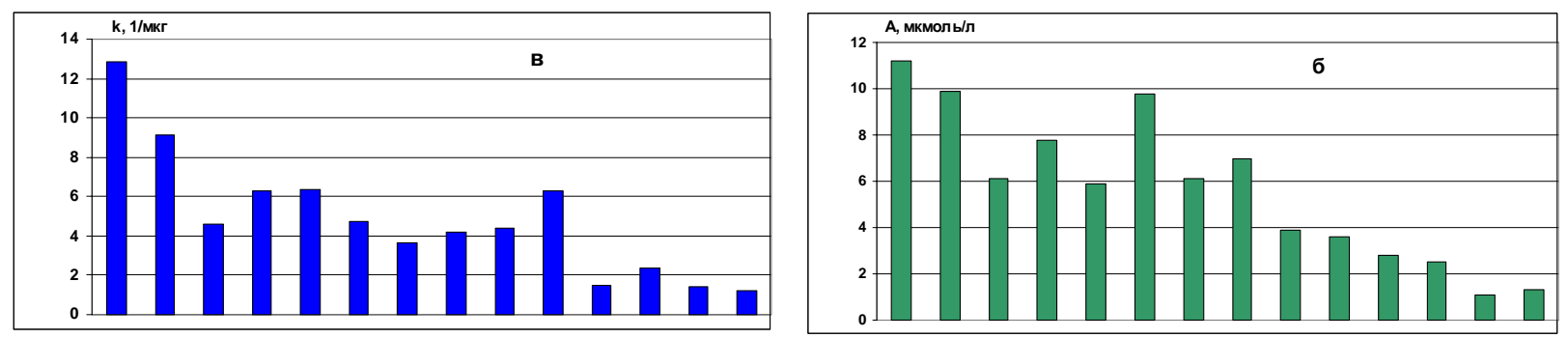

Рис. 4. а - суммарная активность (С, мкг/л ГК) фенольных АО в соках Каланхое (амперометрический метод), б - суммарная активность (А, мкмоль/л) соков к кислороду и его радикалам (вольтамперометрический метод), в - суммарная АОА соков ( $\mathrm{k}, 1 / \mathrm{M \kappa г)} \mathrm{-}$ (хемилюминесцентный метод)

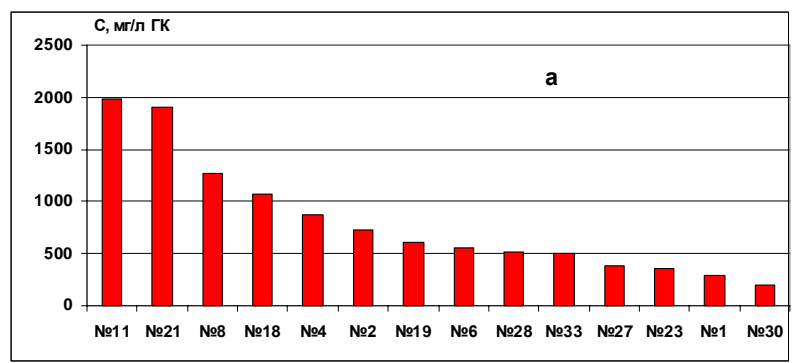

В работах [2, 3] тщательно изучен биохимический состав настоек Каланхое перистого и Каланхое Дегремона разными методами, в том числе и методом ВЭЖХ. В соках листьев и стеблей указанных видов Каланхое содержатся флавоноиды: кверцетин, кемпферол и их гликозиды, рутин, лютеонин; органические кислоты, основные из которых яблочная, изолимонная и лимонная. Идентифицированы 15 аминокислот, среди которых в количественном отношении преобладает глутаминовая кислота, затем аспарагиновая кислота и глицин. Каланхое богат полисахаридами (35-40\%), присутствуют в нем конденсированные танины, сапонины, производные холестерина, метиловые эфиры, а также витамины: аскорбиновая кислота, тиамин, рибофлавин и микроэлементы: цинк, железо, кальций, натрий, калий и др. [2]. Делается вывод о значительном сходстве качественного состава фенольных и других соединений в этих двух видах Каланхое [3]. Возможно, это относится и к другим видам.

Надо отметить, что все три метода демонстрируют значительно более высокую антиоксидантную активность соков двух представителей рода Каланхое: K.scapigera и K.rhombopilosa по сравнению с популярными и широко используемыми в лечебных целях K.pinnata №1 и K.daigremontiana №6. Для расшире- 
ния возможности использования указанных видов Каланхое как источников биологически активных соединений необходимо проведение дополнительных исследований соков этих растений на предмет изучения их биохимического состава, а также антибактериальных, противомикробных, фиторегулирующих и других свойств компонентов этих растений. Возможно, они окажутся более перспективными и для использования их в медицине.

\section{Выводы}

Проведен сравнительный анализ результатов измерений АОА соков 14 различных видов Каланхое тремя методами: амперометрическим, вольтамперометрическим и хемилюминесцентным. Наилучшую корреляцию результатов $(\mathrm{r}=0,89)$ показали амперометрический и хемилюминесцентный методы. Среди изученных образцов выявлены два наиболее активных с точки зрения АОА представителя рода Каланхое: K.scapigera и K.rhombopilosa. Они могут оказаться более перспективными источниками биологически активных соединений по сравнению с использующимися в настоящее время видами Каланхое.

\section{Список литературы}

1. Семенова Л.В., Ямпольский Ю.В. Лекарственные экзотические растения. Вып. 1. СПб., 2003. 125 с.

2. Волжанова М.И., Байльман Р.А., Суслина С.Н., Быков В.А. Каланхое перистое и дегремона: химический состав, применение в медицине (обзор) // Вопросы биологической, медицинской и фармацевтической химии. 2010. №7. С. 14-20.

3. Волжанова М.И., Суслина С.Н., Быков В.А. Сравнительное исследование целевой части метаболома близких видов каланхое хроматографическими методами // Вопросы биологической, медицинской и фармацевтической химии. 2011. №8. С. 3-6.

4. Анисимов М.М., Герасименко Н.И., Чайкина Е.Л., Серебряков Ю.М. Биологическая активность метаболитов лекарственного растения Kalanchoe daigremontiana (Hamet de la Bbthie) Jacobs et Perr. // Известия РАН. Серия биологическая. 2009. №6. С. 669-676.

5. Мисин В.М., Сажина Н.Н., Вандышев В.В., Хомик А.С. Сравнительный анализ содержания антиоксидантов и уровня их активности в соках суккулентных растений амперометрическим и вольтамперометрическим методами // Вопросы биологической, медицинской и фармацевтической химии. 2010. №12. С. 1-5.

6. Оленников Д.Н., Зилфикаров И.Н., Торопова А.А., Ибрагимов Т.А. Химический состав сока каллизии душистой и его антиоксидантная активность // Химия растительного сырья. 2008. №4. С. 95-100.

7. Яшин А.Я. Инжекционно-проточная система с амперометрическим детектором для селективного определения антиоксидантов в пищевых продуктах и напитках // Российский химический журнал. 2008. T. LII, №2. C. $130-135$.

8. Peyrat-Maillard M.N, Bonnely S., Berset C. Determination of the antioxidant activity of phenolic compoundsby coulometric detection // Talanta. 2000. Vol. 51. Pp. 709-715.

9. Korotkova E.I., Karbainov Y.A., Avramchik O.A. Investigation of antioxidant and catalytic properties of some biological-active substances by voltammetry // Anal. and Bioanal. Chem. 2003. Vol. 375, N1-3. Pp. 465-468.

10. Теселкин Ю.О., Бабенкова И.В., Любицкий О.Б., Клебанов Г.И., Владимиров Ю.А. Ингибирование сывороточными антиоксидантами окисления люминола в присутствии гемоглобина и пероксида водорода // Вопросы медицинской химии. 1997. Т. 43, №2. С. 87-93.

11. Сажина Н.Н., Мисин В.М., Короткова Е.И. Измерение антиоксидантной активности экстрактов смесей чая электрохимическими методами // Химия растительного сырья. 2011. №2. С. 137-143.

Поступило в редакичю 19 сентября 2012 г.

После переработки 25 ноября 2012 2. 
Sazhina N.N..$^{*}$, Lapshin P.V. ${ }^{2}$, Zagoskina N.V. ${ }^{2}$, Korotkova E.I. ${ }^{3}$, Misin V.M. ${ }^{1}$ COMPARATIVE ANALYSIS OF KALANCHOE JUICE ANTIOXIDATIC ACTIVITY

${ }^{I}$ N.M. Emanuel Institute of Biochemical Physics, Russian Academy of Sciences, ul. Kosygina, 4, Moscow, 119334

(Russia),e-mail: Natnik48s@yandex.ru

${ }^{2}$ K.A. Timirjazev Institute of Plant Physiology, Russian Academy of Sciences, RAS,

ul. Botanicheskaia, 35, Moscow (Russia),e-mail: phenolic@ippras.ru

${ }^{3}$ Tomsk Polytechnic University, pr. Lenina, 30,Tomsk, 634050, (Russia), e-mail: eikor@mail.ru

Now the special attention to studying of antioxidant activity of various herbs is given for the purpose of search among them the most active sources of biologically active components. In this work for this purpose the comparative analysis of measurement results of the total antioxidatic activity for juice of 14 different types of Kalanchoe (Kalanchoe L.) is carried out by three methods: ammetric, voltammetric and chemiluminescence. Among the studied samples two most active kinds of Kalanchoe are exposed: K.scapigera and K.rhombopilosa. They can appear more perspective sources of biologically active components in comparison with types which are used now.

Keywords: antioxidants, ammetric, voltammetric, chemiluminescence methods, polyphenols, Kalanchoe.

\section{References}

1. Semenova L.V., Iampol'skii Iu.V. Lekarstvennye ekzoticheskie rasteniia. [Medicinal exotic plants]. St. Petersburg, 2003, no. 1, 125 p. (in Russ.).

2. Volzhanova M.I., Bail'man R.A., Suslina S.N., Bykov V.A. Voprosy biologicheskoi, meditsinskoi i farmatsevticheskoi khimii, 2010, no. 7, pp. 14-20. (in Russ.).

3. Volzhanova M.I., Suslina S.N., Bykov V.A. Voprosy biologicheskoi, meditsinskoi i farmatsevticheskoi khimii, 2011, no. 8, pp. 3-6. (in Russ.).

4. Anisimov M.M., Gerasimenko N.I., Chaikina E.L., Serebriakov Iu.M. Izvestiia RAN. Seriia biologicheskaia, 2009, no. 6, pp. 669-676. (in Russ.).

5. Misin V.M., Sazhina N.N., Vandyshev V.V., Khomik A.S. Voprosy biologicheskoi, meditsinskoi i farmatsev-ticheskoi khimii, 2010, no. 12, pp. 1-5. (in Russ.).

6. Olennikov D.N., Zilfikarov I.N., Toropova A.A., Ibragimov T.A. Khimiia rastitel'nogo syr'ia, 2008, no. 4, pp. 95-100. (in Russ.).

7. Iashin A.Ia. Rossiiskii khimicheskii zhurnal, 2008, vol. LII, no. 2, pp. 130-135. (in Russ.).

8. Peyrat-Maillard M.N, Bonnely S., Berset C. Talanta, 2000, vol. 51, pp. 709-715.

9. Korotkova E.I., Karbainov Y.A., Avramchik O.A. Anal. and Bioanal. Chem., 2003, vol. 375, no. 1-3, pp. $465-468$.

10. Teselkin Iu.O., Babenkova I.V., Liubitskii O.B., Klebanov G.I., Vladimirov Iu.A. Voprosy meditsinskoi khimii, 1997, vol. 43, no. 2, pp. 87-93.

11. Sazhina N.N., Misin V.M., Korotkova E.I. Khimiia rastitel'nogo syr'ia, 2011, no. 2, pp. 137-143.

Received September 19, 2012

Revised November 25, 2013

\footnotetext{
* Corresponding author.
} 
